\title{
L-lysine/L-arginine-containing Amino Acid
}

National Cancer Institute

\section{Source}

National Cancer Institute. L-lysine/L-arginine-containing Amino Acid. NCI Thesaurus.

Code C157025.

An intravenous (IV) amino acid (AA) solution containing the cationic amino acids L-lysine and L-arginine, with radioprotective activity. Upon IV administration of the AA solution, Llysine and L-arginine are specifically taken up by the kidneys. This protects the kidneys from toxicity by certain co-administered radio-labeled peptides as they compete with radio-labeled peptides for renal uptake. This reduces uptake of the radio-labeled peptides by the kidneys and decreases their renal retention. It also increases the target-to-kidney ratio of the radio-labeled peptides, thereby reducing radiation exposure to the kidneys and preventing nephrotoxicity. 